"AIR POLLUTION AND THE AUTOMOBILE"

\author{
by \\ G.F. HARRISON \\ TECHNICAL MANAGER, \\ THE ASSOCIATED OCTEL COMPANY LT D., \\ LONDON, ENGLAND.
}

Mr. G.F. Harrison, the technical manager of the Associated Octel Company, which produces a very high proportion of the tetra ethyl and tetramethyl lead used as an anti-knock additive in petrol gave an address to members of the Clean Air Association during his visit to South Africa in June. The following is an extract from his talk.

\title{
Carbon Monoxide
}

The most toxic constituent and the one occurring in the highest concentration in the exhaust gas of gasoline engined vehicles is carbon monoxide, which is formed by the imcomplete combustion of the fuel. The amount emitted depends on the adjustment of the carburetter and on the engine load, usually being highest during periods of idling. An average value for European type cars not modified to reduce emissions, would be $7 \%$ by volume at idle.

Extensive measurements of the carbon monoxide cencentration in the air in cities have been made for a number of years. It has been shown that the amount present correlates well with the volume of traffic, usually showing two peaks of concentration corresponding with the morning and evening rush hours. During such times concentrations of up to $20 \mathrm{ppm}$, averaged over one hour are not unusual, and maximum values of $100 \mathrm{ppm}$ have bieen recorded. 
There are, of course, sources of carbon monoxide other than motor vehicles. In the U.S.A. as a whole, it has been estimated that gasoline engines produce about $58 \%$ of the total carbon monoxide, stationary combustion processes 1,9\%, industrial processes $11 \%$, agriculture etc. 9,5\% and forest fires 7\%. (3). The total mass of CO released into the atmosphere from these sources is estimated to be about 100 million tons per annum but, in spite of this, the background CO level is not apparently increasing. It has recently been found that micro-organisms (Aspergillus spp and Penicillium spp) in the soil of the USA would be able to remove twice the entire global production of $\mathrm{CO}$. (4).

The toxic properties of $\mathrm{CO}$ are due to its powerful affinity for haemoglobin, with which it reversibly combines to form carboxyhaemoglobin $\mathrm{COHb}$., thus reducing the oxygen-carrying capacity of the blood. For any given concentration of $\mathrm{CO}$ in the air there is an equilibrium value of $\mathrm{COHb}$. in the blood, e.g. exposure to $30 \mathrm{ppm}$ CO will result in a $\mathrm{COHb}$. concentration of approximately 5,2\%. The attainment of this equilibrium value, however, takes time - for the example quoted, a period of more than 8 hours or so would be required. Cigarette smoke contains large quantities of CO - up to 2\% (20 000 ppm) - and the blood of a reasonably heavy smoker could contain 5 to $7 \% \mathrm{COHb}$.

For healthy individuals a $\mathrm{COHb}$. concentration of $5 \%$ is probably without significance - indeed Stewart et al (5) claim that no effects are noticeable at values below $12,5 \% \mathrm{COHb}$. In individuals suffering from anaemia, heart of pulmonary disease or any condition which interferes with or restricts oxygen transport, the presence of any $\mathrm{COHb}$. in the blood may impose an additional burden. Numerous studies have been made in an attempt to correlate $\mathrm{CO}$ concentrations in the air with mortality but so far no unequivocal correlation has been demonstrated. 


\section{Hydrocarbons}

There are three sources of hydrocarbon emissions from motor vehicles, the exhaust system, the crankcase breather and evaporation from the fuel tank and carburetter. The so-called 'unburned hydrocarbons' in the exhaust gas arise from incomplete combustion of the fuel-air mixture in the combustion chamber caused by lack of oxygen or by quenching of the reaction by the cool cylinder walls. Any fuel-air mixture or products of combustion passing the piston rings escapes from the crank case through the breather pipe, this accounts for 20-25\% of the total hydrocarbon emissions. If the engine is stopped when it is hot (which it usually is), fuel in the float chamber of the carburetter rapidly evaporates. Fuel vapour is always displaced from the tank during filling and during 'breathing' induced by temperature changes.

There are several ways of expressing the amount of any constituent of exhaust gas, e.g. as ppm, as grams per mile* run, or as grams per test. Probably the most widely used measure, introduced by the U.S. Government, is grams of pollutants per mile run, measured over a strictly controlled cycle of driving which includes starting, idling, accelerating, cruising, decelerating, etc. Using this method, an average European type car, with no emission control modifications, could emit up to $6 \mathrm{~g} / \mathrm{mile}$ of unburned hydrocarbons, and a further $1,5 \mathrm{~g} / \mathrm{mile}$ as crankcase blowby.

Hydrocarbons are produced by many natural processes, e.g. the decomposition of vegetable matter (methane) and by evaporation from trees, etc., (terpenes). It has been estimated $\underline{(6)}$ on a global basis that natural hydrocarbon production is some four times that of man-made pollution.

An estimate prepared in the USA in 1968 suggests that motor vehicles account for about $50 \%$ of man-made hydrocarbon pollution and organic
* $\quad 1$ mile
1 kilometre
$=1,609$ kilometre
$=0,621 \mathrm{mile}$ 
solvent evaporation (from paint, etc.) accounts for another $10 \%$.

Although on occasions all other hydrocarbon concentrations drop to unmeasurably low levels, methane concentrations do not. Numerous measurements suggest a world wide minimum methane concentration of $1,0-1,5 \mathrm{ppm}$. In inhabited areas, concentrations up to $6 \mathrm{ppm}$ have been recorded for methane and 1 to 2 ppm for non-methane hydrocarbons.

At the concentrations found in the atmosphere, hydrocarbons exert no direct toxic effect on man or animals although there is evidence that very low concentrations of ethylene, $0,01-0,1 \mathrm{ppm}$, can cause extensive damage to many varieties of plants.

The main interest in hydrocarbon pollution and the reason for the present stringent controls in hydrocarbon emissions in USA is because of the participation of these substances in the photochemical 'smog' reaction. Hydrocarbons differ markedly in their reactivity towards nitrogen oxides, the most reactive being the unsaturated olefins and diolefins and the least reactive, the saturated normal paraffins, e.g. methane, ethane, etc.

\section{Oxides of Nitrogen}

Of the various oxides of nitrogen, the most important as air pollutants are nitric oxide (NO) and nitrogen dioxide $\left(\mathrm{NO}_{2}\right)$. The term $\mathrm{NO}_{\mathrm{x}}$ is used to represent the composite composition of nitric oxide and nitrogen dioxide, be it in the atmosphere or in exhaust gas.

Nitric oxide (NO) and a much smaller amount of dioxide $\left(\mathrm{NO}_{2}\right)$ are formed by combination of atmospheric oxygen and nitrogen under the high temperature conditions associated with combustion processes. The amounts formed, and hence the concentration in the exhaust gas of gasoline engines, depend critically on the air-fuel ratio and on the 
Both $\mathrm{NO}$ and $\mathrm{NO}_{2}$ concentrations show distinct diurnal variations, dependent on the intensity of ultra-violet radiation, the meteorological conditions and the traffic patterns in the sampling area.

NO concentrations also show a marked seasonal variation with high values during the winter months but $\mathrm{NO}_{2}$ does not show this pattern.

Peak values of 1 ppm of $\mathrm{NO}$ and $0,5 \mathrm{ppm}$ of $\mathrm{NO}_{2}$ are not unusual but daily averages, e.g. in Los Angeles, vary from 0,30 ppm NO (winter) to 0,1 ppm NO (summer) with $\mathrm{NO}_{2}$ about $0,09 \mathrm{ppm}$ over the whole year.

At present there are no data from either animal or human studies which suggest that $\mathrm{NO}$ is a health hazard at concentrations found in ambient air, although it has a toxic potential because it can be oxidised to $\mathrm{NO}_{2}$. It is considered that $\mathrm{NO}_{2}$ is about four times as toxic as NO, and there is some indication from animal studies that irreversible changes in the lung structure can be caused by prolonged exposure to concentrations as low as 0,5 ppm. It is of interest to note that the Maximum Allowable Concentration (MAC) for industrial exposure for 8 hours per day, 5 days per week, for a working lifetime is $5 \mathrm{ppm}$, some 50 times the daily average for Los Angeles.

Oxides of nitrogen are, of course, of great importance as reactants in the photochemical smog reactions. During these reactions, NO is converted to $\mathrm{NO}_{2}$ more rapidly than would be the case under more normal conditions, and ozone is produced. $\mathrm{NO}_{2}$ is responsible for the brown colourisation usually associated with photochemical smog. Ozone is probably the most damaging substance found in the atmosphere. (MAC for ozone - 0,1 ppm.)

\section{Particulate Matter}

In addition to the gaseous constituents, - $\mathrm{CO}, \mathrm{HC}, \mathrm{NO}_{\mathrm{x}}$ - exhaust gas from motor vehicles contains varying quantities of particulate matter. Only limited work has been done on the characterisation of such 
material but it can be shown that compounds of lead, iron, calcium, barium and zinc are present, together with carbon and tarry carbonaceous matter. Attention has been focused largely on the lead compounds which arise from the decomposition of tetra-alkyl lead added to the fuel to increase its resistance to knock (octane rating). The quantity of lead alkyl used depends on the composition of the base stock and the octane rating required and varies between the equivalent of $0,1 \mathrm{~g}$ of lead/litre to $0,63 \mathrm{~g}$ of lead/litre, the maximum usually being set either by local legislation or by industry agreement.

The concentration of lead in the exhaust gas varies widely, being influenced by the speed and load of the engine and the age and general conditions of the exhaust system. Taken over a protracted distance say, 25000 miles, about $70 \%$ of the lead introduced with the fuel is emitted from the exhaust, the balance being retained in the engine, in the lubricating oil and in the exhaust system. On this basis, a typical European car would emit about $0,1 \mathrm{~g}$ lead/mile run, together with perhaps $0,2 \mathrm{~g}$ of other particulate material.

Lead in the exhaust gas occurs in a variety of chemical forms, such, for example, as the chloride, bromide, chlorobromide, sulphate, oxide and as complexes with ammonia and phosphorus. The apparent particle size varies between $0,01 \mu(1 \mu=0,001 \mathrm{~mm})$ and $10 \mu$, but recently Lawther et al $\underline{(8)}$ on the basis of electron micrographs, have suggested that the primary lead particles are extremely small circa $0,01 \mu$ - and that they are found on the surface of larger particles of what appear to be carbonaceous matter. These authors also suggest that part of the lead may be present as a dilute solid solution in some of the less dense material.

From the earliest days of the use of tetraethyl lead - about 1923 it was recognised that a substantial part of the lead added to the fuel would be emitted with the exhaust gas and fears were expressed that this lead would pose a hazard to the health of the population at large. 
Recently the health aspects have been the subject of a study by the National Academy of Sciences of the USA. This has been, so far as we know, the most exhaustive study ever conducted (9) and in the preface to the report it is stated that "... lead attributable to emission and dispersal into general ambient air has no known harmful effect".

Lead is an ubiquitous constituent of the earth's crust, ranging in concentration from a few parts per million to many hundreds of parts per million, with an average value of $16 \mathrm{ppm}$.

Because of its ubiquitous nature it is absorbed, together with other trace elements, by plants and animals which, in turn, form the diet of Man. Since lead has always been a constituent part of the diet of man, it must be concluded that man has always had a level of lead within his body which was not the result of any industrial activity. This fact was not appreciated up to the time Professor R.A. Kehoe of the University of Cincinnati, USA, published his data in 1933. Since then, he and other workers in the field of environmental health, using analytical methods of ever increasing precision and sensitivity, have demonstrated that the average adult takes into his body between 0,15 and $0,45 \mathrm{mg}$ of lead per day, of which 0,12 to 0,35 $\mathrm{mg}$ comes from food and drink and 0,03 to $0,10 \mathrm{mg}$ comes from the air. Lead gets into the air from a variety of sources - e.g. the burning of wood and coal, from soil, from the weathering of lead-based paint and, in urban areas, from automobile exhausts.

About $90 \%$ of the lead ingested traverses the alimentary canal unabsorbed and is discharged in the faeces. To this lead is added that portion secreted into the alimentary canal in the biliary, digestive and mucous secretions, with the result that the amount of lead in the faeces is practically equivalent to that in the food and drink consumed. The amount excreted in urine averages between 0,02 and 0,04 mg per day and small, but significant, quantities may be excreted in the sweat, in hair, desquamating skin and nails. Of the lead 
taken into the lungs, part is absorbed, part exhaled and part, trapped in mucus, etc., is swallowed. It is a problem of great difficulty to establish the proportion actually absorbed into the body system but there is evidence that it is very small.

It has thus been shown, primarily by the work of Kehoe, that contrary to popular belief, under normal conditions the body is in equilibrium with respect to lead, the intake being largely balanced by the output in faeces, urine, etc. etc.

The concentrations of lead in the soft tissues of the body - such as the liver, kidneys, brain, blood etc., remain remarkably constant throughout life. Only in the dense parts of the hard bones is accumulation seen to occur with the passage of years. The concentrations of lead in bone, however, bear no relationship to the concentrations observed in the soft tissues of individual subjects which would seem to indicate that the lead in bone is immobile and incapable of influencing soft tissue levels. The lead contained in the bones of an adult may account for as much as $95 \%$ of the total lead in the body. It has been suggested that during certain types of illness or disease this lead may be released from the bone and give rise to lead poisoning, but there is no evidence whatsoever that this occurs.

The concentration of lead in the blood is regarded as providing a good index of the total lead content of the soft tissues of the body at any particular time. In 1967 the World Health Organisation (10) reported an international study of the lead content of the blood of 'normal' people from 16 different countries. Average blood lead values varied from a high of $26 \mu \mathrm{g} / 100 \mathrm{~g}$ in Finland to a low of $7 \mu \mathrm{g} / 100 \mathrm{~g}$ in Peru. Other values were, for example, $18 \mu \mathrm{g} / 100 \mathrm{~g}$ in USA, $23 \mu \mathrm{g} / 100 \mathrm{~g}$ in Britain and $10 \mu \mathrm{g} / 100 \mathrm{~g}$ in Sweden. Of particular interest is the value of $22 \mu \mathrm{g} / 100 \mathrm{~g}$ found for the average of the primitive people of New Guinea who live far removed from cities and man-made sources of lead. ( $1 \mu \mathrm{g}=1$ microgram) 
Although the average value for the lead concentration in blood is, as shown above, about $17 \mu \mathrm{g} / 100 \mathrm{~g}$, there is a wide variation in individual values, anything between say, 10 and $40 \mu \mathrm{g} / 100 \mathrm{~g}$ being considered 'normal'. Half a century of experience among lead workers has shown that there is no evidence of poisoning, however slight, at blood lead levels of less than $80 \mu \mathrm{g} / 100 \mathrm{~g}$ - a figure far in excess of that found under normal circumstances.

There is extensive information regarding the lead content of the air largely derived from surveys made in USA but supported by work in Germany, Switzerland, UK, etc. Two of the most comprehensive surveys of lead in air and lead in blood carried out in recent times are the 'Three City Survey' (11) and the 'Seven City Survey' (12). The first was carried out in 1961-62 in Cincinnati, Los Angeles and Philadelphia; the second in 1968-1971 in the same three cities, with the addition of. Washington, New York, Chicago and Houston. Los Alamos, an area of low exposure to atmospheric metals, was included as a control.

Examination of the blood of about 2000 residents in these cities showed that the lead content did not correlate with the lead in air, which varied from an average value in Los Alamos of $0,17 \mu \mathrm{g} / \mathrm{m}^{3}$ to $3,39 \mu \mathrm{g} / \mathrm{m}^{3}$ in Pasadena, Los Angeles. On the other hand, the blood lead did correlate closely with the lead content of the faeces, which is usually regarded as an accurate indication of the lead content of the food.

Jones and Commins have found that the lead (13) concentrations in the blood of night time taxi drivers does not differ appreciably from that of day time drivers, although higher carboxyhaemoglobin levels in the latter reflect the higher concentration of pollution experienced during the day. They conclude that the contribution of inhaled particulate lead to the total blood lead must be small.

The Maximum Allowable Concentration (MAC) of lead-in-air applicable 
to industrial situations is $150 \mu \mathrm{g} / \mathrm{m}^{3}$. This means that workers in industry may be exposed to air containing up to $150 \mu \mathrm{g} / \mathrm{Pb} / \mathrm{m}^{3}$ for eight hours per day, five days per week for a whole working lifetime, without detriment to health. Experience gained during fifty years of careful observations has proved the validity of this air standard.

Recently, there has been a great deal of interest in the action of lead on certain enzyme systems in the body. In particular, it has been claimed that the enzyme D-amino laevulinic acid dehydrogenase, which is involved in the chain of normal haemoglobin synthesis, is inhibited by lead at levels of concentration in blood which are usually considered to be 'normal' in the general population. The full significance of these results is not yet known and much more work needs to be doneespecially since no other biochemical changes were noted in the subjects investigated, all of whom were normal healthy individuals.

It has been inferred, if not actually stated, that if a lot of lead is toxic, then a little lead must be a little toxic. In this connection, it is of significance to note the statement in the World Health Organisation's Technical Report No. 406, entitled 'Research Into Environmental Pollution' (14).

"If man did not have such biochemical mechanism to take care of foreign substances entering the body, he would have succumbed to the many substances in nature that are foreign to him but are known to penetrate into his body; many of these are harmful when absorbed in large doses. This agrees with the experience that all toxic substances so far investigated (with the possible exception of mutagenic, teratogenic or carcinogenic substances) have been found in experiments on animals, to have - even with prolonged exposure - a minimum dose rate below which no detectable effect on health occurs within the normal life span."

This statement does not, of course, imply that the present levels of lead intake are below the 'threshold' value. The fact that no ill 
effects have been unequivocably demonstrated during many decades of intensive investigation, strongly supports the belief that present levels are, indeed, below the threshold.

\section{REFERENCES}

1. The Progress and Effects of Smoke Control in London. A Report to the General Purposes Committee of London Borought Assocn. Feb. 1970 .

2. First Report of the Royal Commission on Environmental Pollution. Command No. 4585. Feb. 1971.

3. Air Quality Criteria for Carbon Monoxide. U.S. Department of Health, Education and Welfare, March 1970.

4. The Soil as a Natural Sink for Carbon Monoxide. R.E. Inman and R.B. Ingersoll. Stanford Research Institute, California. (Presented at 64th Annual Meeting of the Air Pollution Control Association, Atlantic City, New Jersey, June 27 - July 2nd, 1971.

5. Experimental Human Exposure to Carbon Monoxide.

R.D. Stewart et al.

Department of Environmental Medicine, Marquette School of Medicine, Milwaukee. Presented at 1971 Automotive Air Pollution Research Symposium, Chicago, May 3rd - 5th, 1971.

6. Sources, Abundance and Fate of Gasious Atmospheric Pollutants. Final Report of the Stanford Research Institute, California. E. Robinson and R.C. Robbins, Feb. 1968.

7. Air Quality Criteria for Nitrogen Oxides. Environmental Protection Agency, Washington D.C., January 1971.

8. Airborne Lead and its Uptake by Inhalation. P.J. Lawther, et al. M.R.C. Air Pollution Unit, London. Presented at a Conference at the Zoological Society of London, 27th January 1972.

9. Biological Effects of Atmospheric Pollutants. LEAD Airborne Lead in Perspective. National Academy of Sciences, Washinton, D.C. 1972.

10. An International Study of 'Normal' Levels of Lead in Blood and Urine. L.J. Goldwater and A.W. Hoover. Arch. Environmental Health, Vol. 15, July 1967. 
11. Survey of Lead in the Atmosphere of Three Urban Communities. US Department of Health, Education and Welfare, January, 1965.

12. A Survey of Air and Population Lead Levels in Selected American Communities. L.B. Tepper and Linda S. Levin. Final Report, December 1972. Department of Environmental Health, University of Cincinnati, Ohio, USA.

13. Blood Lead and Carboxyhaemoglobin Levels in London Taxi Drivers. 'Lancet', p. 302, August 12th, 1972.

14. World Health Organisation. Technical Report Series No. 406, Research into Environmental Pollution, Geneva, 1968. 